\title{
Very rapid multi-odour discrimination learning in the ant Lasius niger
}

\author{
T. J. Czaczkes ${ }^{1}$ (1) P. Kumar ${ }^{1}$
}

Received: 2 July 2020 / Revised: 20 September 2020 / Accepted: 23 September 2020 / Published online: 10 November 2020 (c) The Author(s) 2020

\begin{abstract}
Insects can be very good learners. For example, they can form associations between a cue and a reward after only one exposure. Discrimination learning, in which multiple cues are associated with different outcomes, is critical for responding correctly complex environments. However, the extent of such discrimination learning is not well explored. Studies concerning discrimination learning within one valence are also rare. Here we ask whether Lasius niger ants can form multiple concurrent associations to different reward levels, and how rapidly such associations can be learned. We allowed individual workers to sequentially feed on up to four different food qualities, each associated with a different odour cue. Using pairwise preference tests, we found that ants can successfully learn at least two, and likely three, odour/quality associations, requiring as little as one exposure to each combination in order for learning to take place. By testing preference between two non-extreme values (i.e. between $0.4 \mathrm{M}$ and $0.8 \mathrm{M}$ having been trained to the qualities $0.2,0.4,0.8$ and 1.6) we exclude the possibility that ants are only memorising the best and worst values in a set. Such rapid learning of multiple associations, within one valence and one modality, is impressive, and makes Lasius niger a very tractable model for complex training paradigms.
\end{abstract}

Keywords Discrimination conditioning $\cdot$ Associative learning $\cdot$ Insects $\cdot$ Ants

\section{Introduction}

Associative learning, in which an initially neutral cue (the conditioned stimulus, CS) is associated with a stimulus of innate positive or negative valence (something 'good' or 'bad', an unconditioned stimulus, US), is critical to most animals' survival. Indeed, associative learning is so important that it is almost ubiquitous in the animal kingdom, and beyond (van Duijn 2017).

Insects can form associative memories with very few exposures, and maintain these memories for long periods. Fruitflies (Drosophila melanogaster) can form an association between an odour and a reward in one exposure, which may last up to $24 \mathrm{~h}$ (Krashes and Waddell 2008). Honeybees and ants can learn to associate a sucrose reward

Electronic supplementary material The online version of this article (https://doi.org/10.1007/s00040-020-00787-0) contains supplementary material, which is available to authorized users.

T. J. Czaczkes

tomer.czaczkes@ur.de

1 Animal Comparative Economics laboratory, Institute of Zoology, University of Regensburg, 93053 Regensburg, Germany with a colour, odour, or direction after only one exposure, and retrieve this memory several days later (Menzel 1968; Grüter et al. 2011; Piqueret et al. 2019; Oberhauser et al. 2019; Villar et al. 2020). Ants have even been reported to return to memorised locations after multiple months in winter diapause (Salo and Rosengren 2001). Lasius niger ants can form multi-modal associations, combining visual and odour cues, possibly even after a very limited number of exposures (De Agrò et al. 2020). However, not all social insects perform equally well in odour-association tasks. While Apis mellifera honeybees can learn an odour-reward association in a single proboscis extension response trial (Menzel 1993; Henske et al. 2015; Villar et al. 2020), some stingless bee species, such as Meliponula bocandei, seem to form only weak associations under identical circumstances (Henske et al. 2015). While L. niger ants reach a choice accuracy of $71 \%$ after one round of differential exposure to two odours associated with a reward and a punishment (Oberhauser et al. 2019), Camponotus mus seem to require up to eight such visits to reach comparable accuracy (Dupuy et al. 2006). Moreover, the nature of the neutral stimulus and the valance of the unconditional stimulus can influence learning performance. For example, Desmedt et al. (2017) found that Camponotus aethiops retained an association 
between a negative stimulus (heat) and 1-Hexanol $10 \mathrm{~min}$ after exposure, while they failed to retain a similar association to Octanal. Drosophila larvae successfully learn to associate a reward (fructose) with either light or dark, but seem unable to learn to associate punishments (table salt or quinine) with light levels (Gerber et al. 2004).

Discrimination learning is the ability to learn to associate multiple different conditioned stimuli with different unconditioned stimuli. For example, one odour may be associated with a reward (e.g. sugar) and another with a punishment (e.g. quinine solution), or two odours may be associated with two different reward qualities (e.g. low and high molarity sucrose). Differential association experiments, in which researchers attempt to teach animals to discriminate between stimuli, are the main method by which advanced cognitive abilities such as concept learning, numerosity, transitive inference, and meta-cognition are tested (Perry and Barron 2013; Avarguès-Weber and Giurfa 2013; Tibbetts et al. 2019; Bortot et al. 2020). However, differential conditioning is usually restricted to only two cue associates, one positive and one negative. Experiments with differential conditioning to two cues associated with the same valence, e.g. two rewards of different strength, are less well explored. L. niger ants can form such differential positive associations, as demonstrated in incentive contrast studies (Wendt et al. 2019), but how rapidly such associations can be formed is unknown. In addition, very few studies have attempted to form more than two differential associations. Brembs and Wiener (2006) successfully trained Drosophila flies to four different compound stimuli consisting of combinations of two colours and two shapes, using four 2-min training trials. Each combination of colour and shape predicted one of two US (punishment or no punishment). Tibbetts et al. (2019) successfully trained Polistes paper wasps to associate four pairs of five colours with a choice for one of the colours in each pair. In each colour pair, one of the colours offered safety from electric shocks. Using six 30-s training trials per pair, plus one refresher trial, the wasps reached just under $70 \%$ accuracy. In a test of transitive inference, the wasps were also capable of choosing untrained pairs, implying that they were learning more than simple conditional responses (if A do X, if B do Y), although non-transitive mechanisms were not ruled out. Similarly, Benard and Giurfa (2004) successfully trained honeybees to four pairs of five pattern cues using free-flying bees and rewards for correct choices, although above-chance choice on multiple pairs required 40 trials. Such extensive training prohibits more complex experimental designs.

Identifying an invertebrate model which can rapidly learn multiple (more than two) differential associations in a single modality would open the way to a variety of complex tests of cognition, and especially of economic preference behaviour. The ant Lasius niger is capable of learning odour, visual, and directional cues in only one learning trial (Grüter et al. 2011; Oberhauser et al. 2019; De Agrò et al. 2020) and of learning differential associations within one valence (Wendt et al. 2019). Here we ask whether it can form multiple differential associations, with the same valence, in a limited number of learning trials.

\section{Methods overview}

For a detailed methodological description, see supplement S1.

Eight queenless Lasius niger colonies were studied, which were deprived of food for 4 days prior to testing. The aim of the experiments was to train an ant to associate a certain number of odours $(2,3$, or 4$)$ with a certain sucrose molarity. After training, pairwise preference between the odours were then tested on a Y-maze. Four experiments were run (see Table 1), all following the same design: An individual ant was allowed to find a scented food source at the end of a linear runway scented to match the food source. After feeding, the ant returned to the nest, unloaded the food, and was allowed to return to the apparatus. While unloading, the apparatus was switched so that the reward molarity offered, the reward scent, and the matching runway scent, were changed. Ants were allowed to make repeated visits to the linear runway, experiencing each odour/quality combination between 1 and 4 times.

In experiment 1 we trained two odour/reward combinations, with four exposures to each combination. This experiment reproduces part of Oberhauser et al. (2019), and acts as a demonstration that using food flavourings (as opposed to essential oils) results in efficient learning. Experiment 2 linked three molarities $(0.2,0.6,1.8)$ to three odours, with three exposures to each combination. Experiments 3 and 4 linked four molarities $(0.2,0.4,0.8,1.6)$ to four qualities, with two and one exposure to each combination, respectively.

After training, the linear runway was replaced by a Y-maze offering a pair of the trained odours. The choice of the ant was noted, the ant was returned to the start of the apparatus, and a new odour pair was presented. The odour pairs tested in each experiment are shown in Fig. 1.

Pairwise preferences were tested using exact binomial tests, after finding no colony-level effects using mixed-effect models. A detailed description of the statistical analysis method is given in S1. The entire statistical analysis workflow, with code and output, is provided in S2. Innate odour preference controls showed no strong preference between any of the odour pairs (see S1). 
Table 1 Experiment overview

\begin{tabular}{|c|c|c|c|c|c|c|}
\hline Experiment & Odours & Molarities & $\begin{array}{l}\text { \# Visits to each } \\
\text { combination }\end{array}$ & $\begin{array}{l}\text { Pairwise com- } \\
\text { parisons tested }\end{array}$ & $\begin{array}{l}\% \text { Ants choosing } \\
\text { better odour }\end{array}$ & Sample size \\
\hline 1 & Rose; blackberry & $0.25 ; 1.5$ & 4 & 0.25 vs. 1.5 & $94 \% *$ & 17 \\
\hline 2 & Rose; blackberry; orange & $0.2 ; 0.6 ; 1.8$ & 3 & $\begin{array}{l}0.2 \text { vs. } 0.6 \\
0.6 \text { vs. } 1.8 \\
0.2 \text { vs. } 1.8\end{array}$ & $\begin{array}{l}70 \% * \\
79 \% * \\
93 \% *\end{array}$ & 30 \\
\hline 3 & Rose; blackberry; orange; lemon & $0.2 ; 0.4 ; 0.8 ; 1.6$ & 2 & $\begin{array}{l}0.4 \text { vs. } 0.8 \\
0.2 \text { vs. } 0.4 \\
0.8 \text { vs. } 1.6\end{array}$ & $\begin{array}{l}75 \% * \\
65 \% \\
70 \% *\end{array}$ & 41 \\
\hline 4 & Rose; blackberry; orange; lemon & $0.2 ; 0.4 ; 0.8 ; 1.6$ & 1 & $\begin{array}{l}0.4 \text { vs. } 0.8 \\
0.2 \text { vs. } 0.4 \\
0.8 \text { vs. } 1.6\end{array}$ & $\begin{array}{l}72 \% * \\
56 \% \\
77 \% *\end{array}$ & 44 \\
\hline
\end{tabular}

Note that for all molarity sets, the relative difference from each molarity to the next is fixed within sets. This was done to ensure similarly intense sensory differences between the molarities, following basic psychophysical principles (Gescheider 1997). Associations between specific odours and molarities was varied systematically and blocked with other variables (see S1 for details). Percentages marked with an $*$ differ from $50 \%$ at $\alpha=0.05$

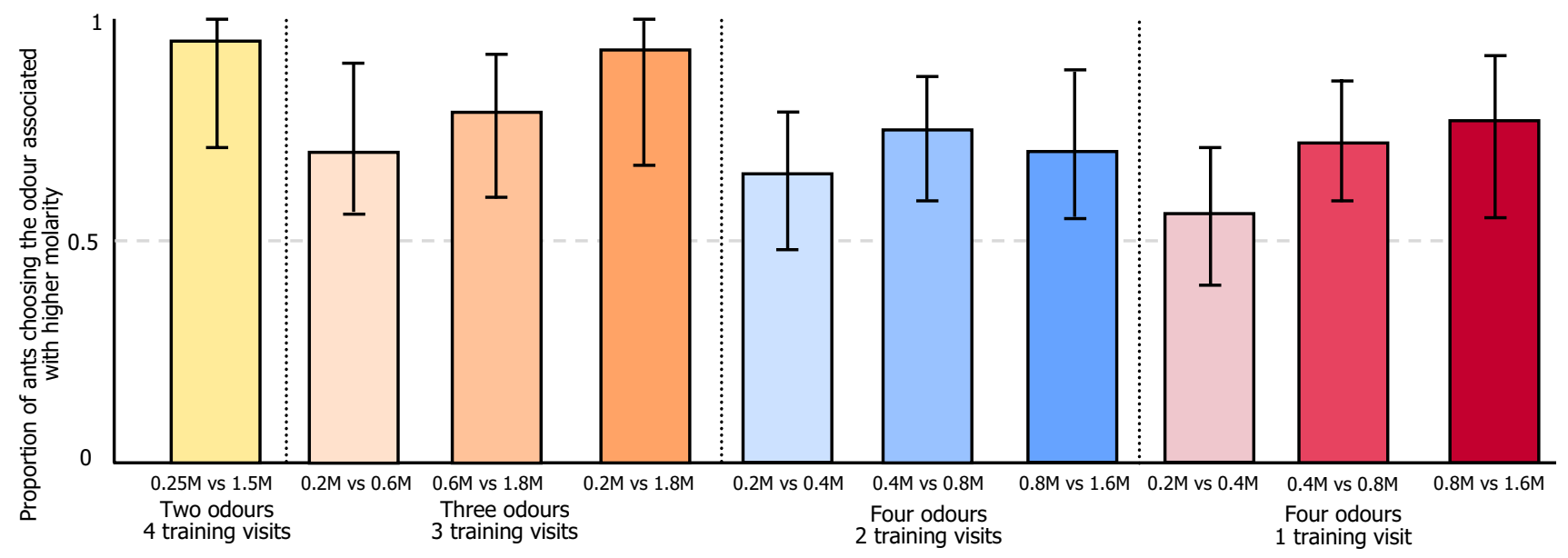

Fig. 1 Proportion of ants choosing the branch of a Y-maze scented with an odour associated with the higher molarity. Shown are all binary choices faced by the ants. Bars are absolute proportions, whiskers are two-tailed exact binomial $95 \%$ confidence intervals

\section{Results}

The ants successfully chose the odour associated with the higher quality in all but two of the pairwise choices (Table 1 and Fig. 1). Specifically:

In experiment 1 (two odour four training visits), most of ants chose the odour associated with the higher molarity $(16 / 17,94 \%, P=0.00027,95 \%$ CI $0.71-0.999)$.

In experiment 2 (three odour three training visits), in the $0.2 \mathrm{M}$ vs $0.6 \mathrm{M}$ test most of the ants $(22 / 29,76 \%$, $P=0.0081$, CI 0.56-0.90) chose the odour associated with $0.6 \mathrm{M}$. Similarly, in the $0.6 \mathrm{M}$ vs $1.8 \mathrm{M}$ test most ants $(23 / 29,79 \%, P=0.023, \mathrm{CI}=0.6-0.92)$ chose the odour associated with $1.8 \mathrm{M}$. Finally, in the $0.2 \mathrm{M}$ vs $1.8 \mathrm{M}$ test, $27 / 29$ (93\%) chose the odour associated with $1.8 \mathrm{M}$ $(P<0.0001, \mathrm{CI}=0.77-0.99)$.
In experiment 3 (four odour two training visits), in the $0.4 \mathrm{M}$ vs $0.8 \mathrm{M}$ test, $30 / 40$ (75\%) of ants chose the odour associated with $0.8 \mathrm{M}(P=0.0022, \mathrm{CI}=0.59-0.87)$. In the $0.8 \mathrm{M}$ vs $1.6 \mathrm{M}$ test $28 / 40$ (72\%) chose the odour associated with $1.6 \mathrm{M}(P=0.0095, \mathrm{CI}=0.55-0.85)$. In the $0.2 \mathrm{M}$ vs $0.4 \mathrm{M}$ test, $26 / 40(65 \%)$ chose the odour associated with $0.4 \mathrm{M}(P=0.08, \mathrm{CI}=0.48-0.79)$.

Finally, in experiment 4 (four odour one training visit), in the $0.4 \mathrm{M}$ vs $0.8 \mathrm{M}$ test $32 / 43(74 \%)$ of ants chose the odour associated with $0.8 \mathrm{M}(P=0.0019, \mathrm{CI}=0.59-0.86)$. In the 0.8 vs $1.6 \mathrm{M}$ test $33 / 43$ (77\%) of ants chose the odour associated with $1.6 \mathrm{M}(P=0.0006, \mathrm{CI}=0.61-0.88)$. However, ants showed no preference in the $0.2 \mathrm{M}$ vs $0.4 \mathrm{M}$ test, with 24/43 (56\%) of ants choosing the odour associated with $0.4 \mathrm{M}(P=0.54$, CI $0.40-0.71)$.

We found no strong evidence of a side bias in experiment 2 , with neither correct side, nor its interaction, showing any 
clear effect (GLMM, $Z<1.17, P>0.24$ ), see Fig. on page 12 of supplement $\mathrm{S} 2$ ). However, in experiment 3 ants showed a left-bias in the $0.2 \mathrm{M}$ vs $0.4 \mathrm{M}$ test, with a strong tendency to make correct decisions when the correct direction was left, and a weaker tendency to make incorrect decisions when the correct decision was right (see Figure in S2). This can be seen in an interaction between correct side and the binary test, with ants in the $0.2 \mathrm{M}$ vs. $0.4 \mathrm{M}$ test making fewer correct decisions than in the $0.4 \mathrm{M}$ vs $0.8 \mathrm{M}$ test when the correct direction was right, but not when it was left $(Z=-2.17$, $P=0.03$ ). Side biases are commonly reported in ants (Hunt et al. 2014; Oberhauser et al. 2020).

Similarly, we found a left bias in experiment $4(Z=-2.33$, $P=0.026$ ). Most ants chose the correct side in all pairwise choices, but this preference was much stronger when the correct side was left (see Figure in S2).

\section{Discussion}

Ant demonstrated very rapid discrimination learning. Even given just one exposure to each of four odour/molarity combinations (experiment 4), ants were able to correctly choose the higher-molarity associated odour of the intermediate pair $(0.4 \mathrm{M}$ vs $0.8 \mathrm{M}) 72 \%$ of the time, and between the two best molarities $(0.8 \mathrm{M}$ vs $1.6 \mathrm{M})$ in $77 \%$ of trials. We can thus definitively claim that they can make at least two odour/molarity associations given only one exposure to each combination.

It is highly likely that the ants can make three such associations given only one exposure. However, as the ants did not reliably distinguish between the $0.2 \mathrm{M}$ and $0.4 \mathrm{M}$ associated odours, we cannot rule out the possibility that neither the $0.2 \mathrm{M}$ nor the $0.4 \mathrm{M}$ associations were formed. We cannot distinguish a choice between $0.8 \mathrm{M}$ and nothing, and between $0.8 \mathrm{M}$ and $0.4 \mathrm{M}$. We thus refrain from claiming that the $0.4 \mathrm{M}$ association was formed. Nonetheless, we think it highly likely that it was, given that when allowed two exposures to each cue/molarity combination, ants make $65 \%$ correct choices (95\% CI 0.48-0.79).

Why did the ants fail to correctly choose between $0.2 \mathrm{M}$ and $0.4 \mathrm{M}$ associated cues? It is possible that a $0.2 \mathrm{M}$ solution is near the detection limit of the ants, and as the detection limit is approached, discrimination ability also suffers, in line with basic psychophysical principles (Gescheider 1997). In a previous experiment, L. niger ants successfully learned to distinguish between $0.1 \mathrm{M}$ and $0.3 \mathrm{M}$ after three visits to each molarity (De Agrò et al. 2019). The ants thus likely struggled to distinguish $0.2 \mathrm{M}$ and $0.4 \mathrm{M}$ with so few exposures. That $0.4 \mathrm{M}$ vs. $0.8 \mathrm{M}$ and $0.8 \mathrm{M}$ vs. $1.6 \mathrm{M}$ were distinguished equally well is also well in line with basic psychophysics, which maintains that differences are sensed in relative terms, as opposed to as absolute deviations from a fixed point.

Examining the speed of differential learning is often hindered in two-combination experiments, as even given a preference for the correct cue, one cannot rule out the possibility that the worst option is simply not learned. This can be demonstrated by further training trials, in which the unrewarded cue is first responded to (due to generalisation) but after several trials is differentiated from the rewarded cue (e.g. (Menzel 1993; Roussel et al. 2012). To demonstrate discrimination learning in just one exposure to each cue, non-extreme cues in a set must be compared, as in experiments 3 and 4 . To our knowledge, this is the first conclusive evidence of such discrimination learning with only one exposure to each associative combination in an insect.

Our results suggest $L$. niger as an ideal invertebrate model for studying complex choice situations involving multiple options. Economic preference experiments, for example looking into menu-effects, is a clear example of a field requiring multiple differential learning. Decoy effects, a subcategory of menu effects, have been studied in ants and honeybees along two trade-off dimensions (Sasaki and Pratt 2011; Tan et al. 2014), but extending into multiple trade-off dimensions has so far been limited by the prohibitive training requirements. L. niger offers itself as an ideal model here, as not only can it learn rapidly, but can also rapidly make multi-modal associations (De Agrò et al. 2020), and can be induced to make many tens of repeat visits in a limited time period (Oberhauser et al. 2020).

Acknowledgements Many thanks to Björn Brembs for his critical reading of the manuscript, and wise suggestions for improvement (some of which we even followed). Thanks also to David Baracchi and an anonymous reviewer for constructive comments and impressive attention to detail. TJC was funded by an Emmy Noether Grant (CZ 237/1-1).

Author contributions TJC conceived of the study, analysed the data, created the figures, and wrote the manuscript. PK collected the data and edited the manuscript.

Funding Open Access funding enabled and organized by Projekt DEAL.

Open Access This article is licensed under a Creative Commons Attribution 4.0 International License, which permits use, sharing, adaptation, distribution and reproduction in any medium or format, as long as you give appropriate credit to the original author(s) and the source, provide a link to the Creative Commons licence, and indicate if changes were made. The images or other third party material in this article are included in the article's Creative Commons licence, unless indicated otherwise in a credit line to the material. If material is not included in the article's Creative Commons licence and your intended use is not permitted by statutory regulation or exceeds the permitted use, you will need to obtain permission directly from the copyright holder. To view a copy of this licence, visit http://creativecommons.org/licenses/by/4.0/. 


\section{References}

Avarguès-Weber A, Giurfa M (2013) Conceptual learning by miniature brains. Proc R Soc B 280:20131907. https://doi.org/10.1098/ rspb.2013.1907

Benard J, Giurfa M (2004) A test of transitive inferences in free-flying honeybees: unsuccessful performance due to memory constraints. Learn Mem 11:328-336. https://doi.org/10.1101/lm.72204

Bortot M, Stancher G, Vallortigara G (2020) Transfer from number to size reveals abstract coding of magnitude in honeybees. iScience. https://doi.org/10.1016/j.isci.2020.101122

Brembs B, Wiener J (2006) Context and occasion setting in Drosophila visual learning. Learn Mem 13:618-628. https://doi.org/10.1101/ $\operatorname{lm} .318606$

De Agrò M, Grimwade D, Czaczkes TJ (2019) Irrational risk aversion in ants is driven by perceptual mechanisms. bioRxiv. https://doi. org/10.1101/620054

De Agrò M, Oberhauser FB, Loconsole M et al (2020) Multi-modal cue integration in the black garden ant. Anim Cogn. https://doi. org/10.1007/s 10071-020-01360-9

Desmedt L, Baracchi D, Devaud J-M et al (2017) Aversive learning of odor-heat associations in ants. J Exp Biol. https://doi.org/10.1242/ jeb. 161737

Dupuy F, Sandoz J-C, Giurfa M, Josens R (2006) Individual olfactory learning in camponotus ants. Anim Behav 72:1081-1091. https ://doi.org/10.1016/j.anbehav.2006.03.011

Gerber B, Scherer S, Neuser K et al (2004) Visual learning in individually assayed Drosophila larvae. J Exp Biol 207:179-188. https:// doi.org/10.1242/jeb.00718

Gescheider GA (1997) Psychophysics: the fundamentals, auflage: revised. Lawrence Erlbaum Assoc Inc, Mahwah

Grüter C, Czaczkes TJ, Ratnieks FLW (2011) Decision making in ant foragers (Lasius niger) facing conflicting private and social information. Behav Ecol Socio Biol 64:141-148. https://doi. org/10.1007/s00265-010-1020-2

Henske J, Krausa K, Hager FA et al (2015) Olfactory associative learning in two African stingless bee species (Meliponula ferruginea and M. bocandei, Meliponini). Insect Soc. https://doi.org/10.1007/ s00040-015-0430-6

Hunt ER, O'Shea-Wheller T, Albery GF et al (2014) Ants show a leftward turning bias when exploring unknown nest sites. Biol Let 10:20140945. https://doi.org/10.1098/rsbl.2014.0945

Krashes MJ, Waddell S (2008) Rapid consolidation to a radish and protein synthesis-dependent long-term memory after singlesession appetitive olfactory conditioning in Drosophila. J
Neurosci 28:3103-3113. https://doi.org/10.1523/JNEUR OSCI.5333-07.2008

Menzel R (1968) Das gedächtnis der honigbienefürspektralfarben. Z Vergl Physiol 60:82-102. https://doi.org/10.1007/BF00737097

Menzel R (1993) Associative learning in honey bees. Apidologie 24:157-168. https://doi.org/10.1051/apido:19930301

Oberhauser FB, Schlemm A, Wendt S, Czaczkes TJ (2019) Private information conflict: Lasius niger ants prefer olfactory cues to route memory. Anim Cogn 22:355-364. https://doi.org/10.1007/ s10071-019-01248-3

Oberhauser FB, Koch A, De Agrò M et al (2020) Ants resort to heuristics when facing relational-learning tasks they cannot solve. Proc R Soc B 287:20201262. https://doi.org/10.1098/rspb.2020.1262

Perry CJ, Barron AB (2013) Honey bees selectively avoid difficult choices. PNAS 110:19155-19159. https://doi.org/10.1073/ pnas. 1314571110

Piqueret B, Sandoz J-C, d'Ettorre P (2019) Ants learn fast and do not forget: associative olfactory learning, memory and extinction in Formica fusca. R Soc Open Sci 6:190778. https://doi.org/10.1098/ rsos. 190778

Roussel E, Padie S, Giurfa M (2012) Aversive learning overcomes appetitive innate responding in honeybees. Anim Cogn 15:135141. https://doi.org/10.1007/s10071-011-0426-1

Salo O, Rosengren R (2001) Memory of location and site recognition in the ant Formica uralensis (Hymenoptera: Formicidae). Ethology 107:737-752

Sasaki T, Pratt SC (2011) Emergence of group rationality from irrational individuals. Behav Ecol 22:276-281. https://doi. org/10.1093/beheco/arq198

Tan K, Latty T, Hu Z et al (2014) Preferences and tradeoffs in nectar temperature and nectar concentration in the Asian hive bee Apis cerana. Behav Ecol Socio Biol 68:13-20. https://doi.org/10.1007/ s00265-013-1617-3

Tibbetts EA, Agudelo J, Pandit S, Riojas J (2019) Transitive inference in Polistes paper wasps. Biol Let 15:20190015. https://doi. org/10.1098/rsbl.2019.0015

van Duijn M (2017) Phylogenetic origins of biological cognition: convergent patterns in the early evolution of learning. Interface Focus 7:20160158. https://doi.org/10.1098/rsfs.2016.0158

Villar ME, Marchal P, Viola H, Giurfa M (2020) Redefining single-trial memories in the honeybee. Cell Rep 30:2603-2613.e3. https://doi. org/10.1016/j.celrep.2020.01.086

Wendt S, Strunk KS, Heinze J et al (2019) Positive and negative incentive contrasts lead to relative value perception in ants. eLife 8:e45450. https://doi.org/10.7554/eLife.45450 